\title{
The art of a hydraulic joint in a spider's leg: modelling, computational fluid dynamics (CFD) simulation, and bio- inspired design
}

DOI:

10.1007/s00359-019-01336-2

\section{Document Version}

Accepted author manuscript

Link to publication record in Manchester Research Explorer

Citation for published version (APA):

Liu, C., Chen, S., Sheng, C., Ding, P., Qian, Z., \& Ren, L. (2019). The art of a hydraulic joint in a spider's leg: modelling, computational fluid dynamics (CFD) simulation, and bio-inspired design. Journal of Comparative Physiology A. https://doi.org/10.1007/s00359-019-01336-2

Published in:

Journal of Comparative Physiology A

\section{Citing this paper}

Please note that where the full-text provided on Manchester Research Explorer is the Author Accepted Manuscript or Proof version this may differ from the final Published version. If citing, it is advised that you check and use the publisher's definitive version.

\section{General rights}

Copyright and moral rights for the publications made accessible in the Research Explorer are retained by the authors and/or other copyright owners and it is a condition of accessing publications that users recognise and abide by the legal requirements associated with these rights.

\section{Takedown policy}

If you believe that this document breaches copyright please refer to the University of Manchester's Takedown Procedures [http://man.ac.uk/04Y6Bo] or contact uml.scholarlycommunications@manchester.ac.uk providing relevant details, so we can investigate your claim.

\section{OPEN ACCESS}


The Art of a Hydraulic Joint in a Spider's Leg: Modelling, Computational Fluid Dynamics (CFD) Simulation, and Bio-inspired Design

Chunbao Liu ${ }^{1,3}$, Shanshi Chen ${ }^{1}$, Chuang Sheng ${ }^{1,3}$, Peng Ding ${ }^{1,3}$, Zhihui Qian $^{3 \Uparrow}$, Lei Ren ${ }^{2,3 \Uparrow}$

1 School of Mechanical Science and Engineering, Jilin University, Changchun 130022, China

2 School of Mechanical, Aerospace and Civil Engineering, University of Manchester, Manchester M13 $9 P L, U K$

3 Key Laboratory of Bionic Engineering, Ministry of Education, Jilin University, Changchun 130022, China

\section{Highlights:}

(1) Fluid dynamics and CFD were combined to investigate the flow state in the tibia-metatarsus joint.

(2) The mechanism of flow inside the leg was analysed.

(3) A bio-inspired hydraulic system was devised based on the flow path of haemolymph in the channel obtained from simulations.

Abstract: Important aspects of spider locomotion rely on a hydraulic mechanism. So far this has not been theoretically analysed. In this work, the flow mechanism of a main hydraulic joint in a spider leg was studied. The purpose is to gain insight into a biohydraulic mechanism using an engineering approach to improve our understanding of the hemolymph flow path in the spider's legs and to contribute to the theoretical analysis of the spider's hydraulic transmission mechanism, thereby providing an inspiration for advanced biomimetic hydraulic systems. During the study, Micro-CT results were used to reconstruct the detailed flow channel. The high pressure areas (inlet, joint, closed leg end) and low pressures in between are also identified. Then, the internal flow field was investigated using CFD (Computational Fluid Dynamics). At the same time, the method of dynamic mesh regeneration, elastic smoothing, is used to simulate muscle contraction and joint extension. The different functions of the channels are substantiated by the velocity profiles. Finally, a bionic hydraulic system was designed according to the trajectory of haemolymph in the flow channel.

\footnotetext{
^Corresponding author: lei.ren@manchester.ac.uk

^Corresponding author: zhqian@jlu.edu.cn
} 
Key words: Bio-inspired; Spider; Hydraulic transmission; Tibia-metatarsus joint; CFD

\author{
Abbreviations \\ CFD Computational fluid dynamics \\ UG Unigraphics
}

\title{
Introduction
}

Hydraulic transmission uses the pressure in a fluid to transmit and control energy and is widely applied in mechanical systems, such as robotics, airplanes, and construction machinery. Compared with mechanical transmission and electrical drive technology, hydraulic transmission has an obvious advantage associated with the power-to-mass ratio. The transmission efficiency in some engineering systems is low because it needs two energy conversions and often is accompanied by leakage, which leads to more energy loss (Xu 2013). For the spider leg, there is no leakage and hence very little energy loss in the energy conversion. Yang and Zhou (2013) reviewed recent developments in fluid power engineering and described the main challenges for hydraulic transmission as follows: increasing the energy efficiency, improving reliability, building smart components and systems, reducing size and weight, reducing environmental impacts, improving and applying energy storage and assessing redeployment capabilities (Yang and Zhou 2013). Spiders use very low internal pressure to achieve efficient driving, and realize the advantages of non-pollution, compact structure, high efficiency, coordinated motion control, stability and reliability, and so on. Natural long-term evolution has contributed to the development of efficient hydraulic transmission components and integrated systems. Studies of the operating mechanisms and energy transfer processes of such a high-performance biological hydraulic system can inspire the development of new driving modes and new energy conversion devices.

Spiders can be functionally regarded as semi-hydraulic systems (Manton and Harding 2009). Parry and Brown (Parry and Brown 1959) studied the relationship between the internal pressure in the leg of an intact spider and the torque on the joint and established an empirical relation. It has been experimentally determined that active extension, which occurs at the hinge joint of the leg, is based on a hydraulic mechanism (Menon and Lira 2006). In the leg, the femur-patella joint and tibia-metatarsus joint are the main pure hydraulic joints, serving as hinge joints with a dorsal axis of rotation and a dorsoventral plane of movement (Zentner 2013). Haemolymph enters the leg via two different pathways. First, it flows into 
the leg arteries and back into the prosoma via venous return channels (Wirkner and Huckstorf 2013). Second, haemolymph flows in lacunae, and this process is highly influenced by intrinsic muscle activity (Kropf 2013). The joint membrane requires special bellow-like folds to prevent unfavourable opposing torque during joint extension compared to when the membranes are isotropic shown by the black arrows in Fig. 1a (Blickhan and Barth 1985).

The body of a spider can be divided into two functional units: the prosoma and opisthosoma (Paul et al. 1989). Hydraulic pressure is generated in the prosoma and the opisthosomal pressures often follow prosomal ones during moderate activity, but the two may also be unlinked (Kropf 2013). The circulatory system of a spider consists of the haemolymph vascular system in combination with a complex system of sinuses and lacunae. The haemolymph vascular system is composed of the central pumping organ, the heart, and arteries (Christians and Stefan 2010). Figure. 1b shows the details of the system from Huckstorfa's work (Huckstorf et al. 2013). Shultz proposed that the suspensor muscles of the endosternite generate most of the prosomal pressure in "hydraulic" arachnids (Shultz 1991; Shultz 2010). However, it seems premature to apply the conclusions drawn from studies of whip scorpions to all arachnids. Hence, the haemolymph pressure in the prosoma may be increased by both muscle sets, and even extrinsic and intrinsic leg muscles may play a substantial role in this process (Fig. 1c) (Whitehead and Rempel 1959; Anderson and Prestwich 1975; Palmgren 1981).

Based on functional analysis, hydraulic transmission in spiders involves an integrated drive and transmission system. To date, the hydraulic transmission process has only been described in function, and previous studies have only been able to reproduce the driving process of the hydraulic joint of a spider in terms of functionality. Such studies have resulted in the "Smart Stick" (Menon and Lira 2006; Lira et al. 2008), fluidic actuators (Spröwitz et al. 2017) and soft robotics (Li et al. 2011; Karakurt et al. 2015) related to spider joints. Based on the nature of hydraulic transmission, it is worthwhile to explore the process and mechanism of transmission involving the internal flow of the hydraulic joint. Therefore, this paper attempts to construct a power transfer model of the joint and combine fluid dynamics and CFD to investigate the flow state in the joint to build a bridge between biological hydraulics and engineering hydraulics and provide inspiration for developments in hydraulic engineering.

To achieve these objectives, SEM and Micro-CT analyses were conducted. Next, the internal flow channel model of the tibia-metatarsus joint was established by Computer Aided Design (CAD). A CFD 
method was applied to analyse the haemolymph flow in the channel, and a bio-inspired hydraulic system was designed based on the simulation results. This hydraulic system is more inclined to the hydraulic system in the engineering sense. The aim is to develop a more efficient and energy efficient hydraulic system based on the proven hydraulic system. The limitation of this hydraulic system is that there is no corresponding resistance value for each hydraulic resistance, and there are still many places to be perfected. This hydraulic system is mainly to simulate the actions of spider legs, only to make a preliminary analysis of the complex hydraulic system inside spider legs, and to lay the groundwork for further research. This work provides insight into the haemolymph flow channel of a spider leg and contributes to the theoretical analysis of the mechanism underlying hydraulic transmission in spiders, thereby providing inspiration for advanced bionic hydraulic systems.

The loss of energy in fluid flow mainly includes the pressure loss along a path and the local pressure loss. In a constant-diameter pipe, the pressure loss due to the internal friction between the fluid and the pipe wall and the fluid itself is known as the loss of pressure along the flow path. The Darcy formula for calculating the pressure loss along path $h_{f}$ is as follows (Chu and Ma 2015):

$$
h_{f}=\lambda \frac{l}{d} \times \frac{v^{2}}{2 g} .
$$

Because this situation is similar to the laminar flow of water in Hagen-Poisseuille regimes (Zhang 1999), so $\lambda$ is as follows:

$$
\lambda=64 / \mathrm{Re} .
$$

The Reynolds number can be calculated as follows:

$$
\operatorname{Re}=\frac{\rho v \mathrm{~d}}{\mu} .
$$

where $\lambda$ is the coefficient of resistance along the path, $l$ is the pipe length $(\mathrm{m}), d$ is the hydraulic diameter of the pipe $(\mathrm{m}), v$ is the average velocity of the fluid $(\mathrm{m} / \mathrm{s}), g$ is the acceleration of gravity, $\rho$ is the density $\left(\mathrm{kg} / \mathrm{m}^{3}\right)$, and $\mu$ is the dynamic viscosity (Pa.s). " $\times$ " is used for multiplication.

When fluid flows in a stationary channel (Fig. 5b), this satisfies the Bernoulli equation, which is applicable to the steady flow of incompressible viscous fluid, as follows:

$$
Z_{1}+\frac{p_{1}}{\rho g}+\frac{\alpha_{1} v_{1}^{2}}{2 g}=Z_{2}+\frac{p_{2}}{\rho g}+\frac{\alpha_{2} v_{2}^{2}}{2 g}+\sum h_{s} .
$$

For incompressible homogeneous fluids, the following flow equation can be derived: $v_{1} A_{1}=v_{2} A_{2}=q$. 
where $A$ is the cross-sectional area of the flow path, $q$ is the rate of flow, $Z$ is the mean value of fluid

potential energy per unit mass, $\frac{p}{\rho g}$ is the mean value of fluid pressure energy per unit mass, $\frac{\alpha v^{2}}{2 g}$ is the mean value of fluid kinetic energy per unit mass, $\sum h_{s}$ is the sum of fluid energy loss per unit mass and $\alpha$ is the kinetic energy correction factor. When the flow is laminar, the correction factor is $\alpha=2$.

\section{Materials and methods}

\section{Spider sample}

The spiders (Selenocosmia hainanum, Theraphosidae) used in this study were collected from Vietnam. Adult female spider (body length ca. $5.4 \mathrm{~cm}$, and body weight up to $12 \mathrm{~g}$ ) were taken into the laboratory and kept individually in plastic boxes (length: $25 \mathrm{~cm}$; width: $15 \mathrm{~cm}$; height: $10 \mathrm{~cm}$ ) with suitable air holes. The bottom of the box was covered with loose coconut soil. A piece of bark and a plastic container (diameter: $3 \mathrm{~cm}$; height: $1 \mathrm{~cm}$ ) filled with fresh water were placed in the uncovered area. The spider was kept under natural light conditions but away from direct sunlight. As the spider adapted to the above living environment, we began to take the steps of cutting off the spider's legs. The spider was anesthetized in a sealed container using diethyl ether. The sterilized defatted cotton ball soaked with ether was first placed in a $1000 \mathrm{ml}$ beaker, then the spider was placed, and the beaker was finally sealed with a plastic film and a rope. When the spider's leg is observed to lose its tightness and is in a contracted state, it is cut from the proximal end of the spider by sharp scissor. All legs contribute similarly to the propulsion of the animal during steady locomotion (Clarke 1986; Reußenzehn 2010). As shown in Fig. 2, we chose the fourth leg on the right side $(R 4)$ of the spider, which has often been selected for study by other researchers (Parry and Brown 1959). The spider leg was placed in a glass specimen bottle (diameter: $8 \mathrm{~cm}$; height: $11 \mathrm{~cm}$ ) containing $10 \%$ fixative solution of formalin and soaked for 1-2 days to ensure the integrity of the tissues. Although the use of formalin fixation causes contraction, the size of the channel given in this paper is not a key parameter in the study and the decreased size has little effect on the final result. Then, SEM and Micro-CT experiments were performed.

\section{Micro-CT}

The inner detailed structure of the flow channel that the SEM failed to reveal was studied with help of 
Micro-CT, which has been used extensively in many research applications. The popularity of this technique is attributed to its ability to provide precise quantitative and qualitative information on the 3D morphology of a specimen (Ho and Hutmacher 2006).

The tibia-metatarsus joint was cut off and the specimen was scanned by a SkyScan-1172 highresolution Micro-CT system at the Institute of Botany, Chinese Academy of Sciences (IBCAS). The beam accelerating voltage and current were set to $95 \mathrm{kV}$ and $72 \mu \mathrm{A}$, respectively. Digital cross sections of the spider were generated numerically using the volumetric reconstruction software NRecon (Skyscan, Bruker, Belgium). The output was a series of 2222 bitmap images of size $2269 * 2108$.

The tibia-metatarsus joint selected in the experiment is shown in Fig. 3a. Micro-CT images at different positions of the tibia-metatarsus joint are shown in Fig. 3b. The entities shown in the picture actually contain skeleton and muscles. Irregular holes are clearly visible in each cross section and constitute the channels for fluid transport.

\section{The reconstructed model of the tibia-metatarsus joint}

The 3D modelling programme Mimics (Materialize, Belgium), which is used by many CAD engineers, is considered the first choice for automatically reconstructing 3D models. However, the challenge of data processing associated with high-resolution Micro-CT images causes this technique to be extremely computationally demanding in terms of the memory and Central Processing Unit (CPU) power. In addition, the generated files are often too large and cannot be effectively handled because of their complex structures. Because such files cannot be used in further CFD calculations, joint reconstruction was performed manually.

Precise 3D structural and geometric positioning information of the joint could be obtained from the Micro-CT data, making it possible to stack the 2D maps to create 3D models. The manual construction method was more efficient in the context of the model than an automatic approach, and the accuracy of the model can be sufficiently guaranteed according to the results of the Micro-CT scanning. The details of the method are given below. Based on an examination of the shape of adjacent pictures, which exhibited almost no change, a certain number of images were selected at successive intervals. The first picture was imported into unigraphics (UG) and positioned in the XOY plane. Then, the image was treated as prior reference to create the first sketch. The boundaries of the orifices were accurately approximated 
during the boundary tracing process. Since the thickness of the virtual slices was $4.5 \mu \mathrm{m}$, the distance from the second plane to the first could be determined based on the serial numbers of the two images. After the second sketch was constructed using the same process, the bodies were established between the orifices at the corresponding locations of the two sketches through the "curve group" command. In addition, the internally formed bodies could be removed using Boolean subtraction. The above operations were executed repeatedly until the entire model was complete. The generated geometric model is shown in Fig. 4a, and the internal flow channel model, as presented in Fig. 4b, provided a platform for the subsequent simulation.

\section{Governing equations}

The internal flow field of the tibia-metatarsus joint was analysed using CFD. A series of previous studies involving the simulation of a hydraulic torque converter conducted by our group (Liu et al. 2015) was used as the basis for this investigation. In view of the complexity of the internal channel structure, the following assumptions were made in the numerical simulation of haemolymph flow within the leg of the spider:

(1) The haemolymph is Newtonian with constant thermophysical properties, and the diameter of the channel is equal to that of the leg segment due to its irregular shape.

(2) The haemolymph flow in the channel is laminar, as the velocity is set to approximately $0.3 \mathrm{~m} / \mathrm{s}$ (Stegen and Grieshaber 2001; Siebert et al. 2010; YU et al. 2015) and the leg diameter is small (approximately $4 \mathrm{~mm}$ ). The Reynolds number $(\mathrm{Re})$ is a physical quantity that characterizes the flow state of the fluid and can be used to distinguish between laminar and turbulent flows. Generally, a Reynolds number less than 2300 reflects a laminar flow. Here, the corresponding Reynolds number is approximately 362 . When the gravity factor is added in the subsequent simulation calculation, there is no change in the calculated results when the gravity factor is not added, which indicates that the gravity factor can be ignored.

(3) The wall surface temperature of the channel is constant.

Based on these assumptions, the haemolymph flow in the channel is governed by the continuity equation, Navier-Stokes equations, which are written below in normalized form (Wang 2004): $\frac{\partial u_{x}}{\partial x}+\frac{\partial u_{y}}{\partial y}+\frac{\partial u_{z}}{\partial z}=0$ 


$$
\frac{\partial u_{i}}{\partial t}+u_{j} \frac{\partial u_{i}}{\partial x_{j}}=-\frac{1}{\rho} \frac{\partial p}{\partial x_{i}}+v \frac{\partial^{2} u_{i}}{\partial x_{j}^{2}}+f_{i}
$$

where $u_{x}, u_{y}$, and $u_{z}$ are the fluid velocities in the $\mathrm{x}, \mathrm{y}$, and $\mathrm{z}$ directions respectively; $u_{i}$ is a velocity component in the direction of $\mathrm{x}$ or $\mathrm{y}$ or $\mathrm{z} ; x_{i}$ is a displacement component in the direction of $\mathrm{x}$ or $\mathrm{y}$ or $\mathrm{z}$; $t$ is the time; $p$ is the pressure; $V$ is the kinematic viscosity; and $f$ is the body force.

\section{Computational setting}

The computational domain of the model is shown in Fig. 4b. The flow channel model was imported into ANSYS ICEM to generate the unstructured tetrahedron grid with 378,325 grid cells, and a grid independence test was then conducted. The test indicated that a finer mesh would not substantially increase the accuracy of the calculations. Therefore, the current mesh number was considered sufficient. The numerical solution for haemolymph flow was obtained using the finite-volume solver ANSYS Fluent ${ }^{\circledR}$. The boundary conditions used were defined as shown in Fig. 4c. Due to the fact that muscle contraction and leg extension can cause volume changes, so it is allowed to have only an inlet and no outlet. At the same time, the second method of dynamic mesh regeneration, elastic smoothing, is used to simulate muscle contraction and joint extension.

Along the wall, a no-slip boundary condition was adopted. The Newtonian haemolymph is incompressible. Its viscosity was $0.0035 \mathrm{~Pa} \bullet$ (Zhang 1999), and the fluid mass density was $1055 \mathrm{~kg} / \mathrm{m}^{3}$ (Biasetti et al. 2011). The SIMPLE algorithm was used to solve for the pressure velocity coupling term. The discretization scheme used was the second-order upwind scheme, and the initialization area was selected from all zones. Additionally, the iteration time step was set to $0.001 \mathrm{~s}$ to ensure that all grid elements were searched in the iterative computation.

\section{Boundary condition verification}

There are many kinds of boundary conditions, such as velocity, pressure and mass. The pressure inlet is first selected as the boundary condition, and then the velocity inlet boundary condition is used for comparison.

1. Pressure inlet boundary condition

For this type of boundary condition, the inner channel of the tibia-metatarsus joint was simplified to clearly determine the inlet pressure values for the spider, as shown in Fig. 5a. The measuring method of 
inserting a needle into the distal end of the tibia to record data from the leg (Stewart and Martin 1974), and the internal pressures (Sensenig 2003) examined the Aphonopelma tibia-metatarsus joint. Pressure values of $2.5 \mathrm{kPa}, 5.3 \mathrm{kPa}$ and $9.8 \mathrm{kPa}$ according to the reference literatures at position 2 (the distal end of the tibia) were initially determined to encompass the range of pressures typically measured in walking and resting arachnids, although much higher pressures have been measured in startled and restrained animals (Alexander 1967; Stewart and Martin 1974; Shultz 1991).

From 1-1 section to 2-2 section, there is only pressure loss along the course, but no local pressure loss. The length of the tibia segment was $14.6 \mathrm{~mm}$, and the diameter was $4.12 \mathrm{~mm}$. The larger diameter is used to simplify the calculation, because the structure of the spider leg is so complicated that it is difficult to measure the cross-section area of the internal runner at different positions using existing techniques. The simplified model is used to represent the cross-sectional areas at different locations of the flow channel by using a fixed-size cross-sectional area. Since the pressure value at position 2 was known, the inlet pressure values (position 1) could be calculated using Equations (1) to (5) and fluid dynamic theory. Firstly, the pressure loss along the path $\left(h_{f}\right)$ is obtained by Equation (1), (2) and (3), that is, $\sum h_{s}$ in Equation (4). The results of CFD calculation show that gravity has no effect on the variation of pressure value, so the gravity factor is not taken into account, so $\mathrm{Z1}$ is equal to $\mathrm{Z} 2$. Since 1-1 and 2-2 have the same cross-sectional area, i.e. A1 equals to A2, $v_{1}$ equals to $v_{2}$ known from Equation (5). In the case of laminar flow, $\alpha_{1}=\alpha_{2}=2$. In summary, when the size of $\mathrm{p} 2$ is known, the value of $\mathrm{p} 1$ can be calculated according to Equation (4). The relationship between the expressions in equation (4) is shown in Fig. 5b. As shown in Table 1, the inlet pressure values calculated from the same known pressure $\left(\mathrm{P}_{2}\right)$ under different velocity conditions exhibit little difference. Because the length of the spider leg is very small, it is reasonable to assume that the pressure of $\mathrm{p} 1$ is independent of velocity and that the pressure difference with $\mathrm{p} 2$ is relatively small. Here, we chose the values of the calculation that contains all the cases, which were $2506 \mathrm{~Pa}, 5308 \mathrm{~Pa}$, and $9811 \mathrm{~Pa}$

2. Velocity inlet boundary condition

For this type of boundary condition, the inlet was a velocity inlet, with velocity values of $0.2,0.3$ and $0.4 \mathrm{~m} / \mathrm{s}$ (Stegen and Grieshaber 2001; Siebert et al. 2010; YU et al. 2015). The other parameters 
remained unchanged.

After the CFD calculations, the mass flow rate $\left(Q_{\mathrm{m}}\right)$ was selected to identify the optimum boundary condition. The mass flow rate of the haemolymph flowing through the channels can be estimated from the known values of the density $(\rho)$, fluid velocity $(v)$ and cross-sectional area (A) of haemolymph flow using Eq. (8):

$Q_{\mathrm{m}}(\mathrm{Kg} / \mathrm{s})=\mathrm{m}(\mathrm{kg}) / \mathrm{t}(\mathrm{s})=\rho \mathrm{V} / \mathrm{t}=\rho \mathrm{A} v \mathrm{t} / \mathrm{t}=\rho \mathrm{A} v$.

The mass flow rates associated with the two boundary conditions were compared with the theoretical values presented in Table 2 . The mass flow rates of the haemolymph under the pressure inlet boundary condition were much less than the values obtained using Eq. (8). Moreover, the values obtained for the velocity inlet condition were approximately one-third of the values determined using Eq. (8). In the course of theoretical calculations, the diameter of the flow channel is assumed to be the diameter of the leg segment. However, these diameters are not actually the same. The actual diameter at the entrance of the tibia section is $4.14 \mathrm{~mm}$ and the actual diameter at the exit is $4.10 \mathrm{~mm}$. Because the diameters of each position of the tibia segment are different, it is not possible to measure each position, so the actual diameter of the tibia segment is replaced by the average of the inlet and outlet diameters. So the actual diameter is simplified to $4.12 \mathrm{~mm}$. The established channel model shown in Fig. 4a shows that the cross-sectional area of the channel is approximately one-third the cross-sectional area of the leg. Hence, the results of the theoretical calculations should be one-third the simulated results. Thus, the results for the velocity inlet boundary condition can be considered reasonable, and this type of condition is more suitable for CFD simulations.

\section{Results}

\section{The internal flow field}

The overall pressure distribution of the flow field in the tibia-metatarsus joint is shown in Fig. 6. Based on the previous pressure boundary conditions (i.e., pressures of $2500 \mathrm{~Pa}$, $5300 \mathrm{~Pa}$, and $9800 \mathrm{~Pa}$ ), the calculated pressure range is reasonable. The overall pressure distributions inside the joint are generally the same at different inlet velocities, and the pressure decreases gradually from the inlet to the end of the metatarsus. At the end of the metatarsus segment, the pressure becomes negative. The negative pressure may be come from a numerical artefact of the CFD simulation software. However, it will not affect the 
trend of the pressure change calculated. In addition, the pressure difference between the inlet and the distal end of the metatarsus increases with increasing inlet velocity. The overall flow velocity of the fluid inside the joint reaches a maximum at an inlet velocity of $0.4 \mathrm{~m} / \mathrm{s}$, and the maximum value is approximately $1.43 \mathrm{~m} / \mathrm{s}$. Because the internal structure of the joint is complex, the narrow local channel will inevitably increase the flow velocity to a certain extent; thus, the overall velocity range shown in the diagram is reasonable. This finding reflects the effectiveness of the CFD simulation method. The initial wall of the computation is set to a non-slip boundary condition, so that the velocity of the overall outline at the boundary is zero.

Cross sections were established at $\mathrm{z}=-0.0092 \mathrm{~m},-0.0035 \mathrm{~m}, 0.0012 \mathrm{~m}$, and $0.0066 \mathrm{~m}$ positions to study the movement of haemolymph in the inner channels of the joint. Because the overall pressure and velocity distribution trends are similar, the local pressure and velocity distributions are displayed only at an inlet speed of $0.3 \mathrm{~m} / \mathrm{s}$, as shown in Fig. $7 \mathrm{a}$ and Fig. $7 \mathrm{~b}$ respectively. In Fig. $7 \mathrm{a}$, the pressure at the remaining cross sections, except at $\mathrm{z}=-0.0092 \mathrm{~m}$, exhibits a gradient in a certain direction. Figure. $7 \mathrm{~b}$ shows that the velocity gradually decreases from the channel centre to the wall, which conforms to the established flow laws. Moreover, in the sections that encompass different blocks, such as $\mathrm{z}=-0.0092 \mathrm{~m}$ and $\mathrm{z}=-0.0035 \mathrm{~m}$, the velocity distribution varies. Although the distance to the inlet is the same, the velocity difference is obvious. Some blocks exhibit zero velocities, and others display velocity increases compared to that at the inlet, which reflects the complexity of the flow.

In order to better explore the flow rule of liquid in spider leg, we also built the model of the femurpatella joint, and imported the model into simulation software for calculation and analysis. The pressure and velocity distributions obtained are shown in Fig. 8 and Fig. 9, respectively. The fluid flow model is set as unsteady laminar flow, and the blood model is an incompressible homogeneous Newtonian fluid (Newtonian blood viscosity is $0.0035 \mathrm{pa} \mathrm{s}$, fluid density is $1055 \mathrm{~kg} / \mathrm{m} 3$ ). According to the actual flow direction of the blood lymphatic fluid in the channel, the boundary condition sets the near body port as the inlet end and the distal body port as the outlet terminal. The model is set to the resistance model with concentrated parameters. The iteration time step is $0.0001 \mathrm{~s}$.

To better understand the haemolymph flow in the tibia-metatarsus joint, the internal velocity streamline was created at an inlet velocity of $0.3 \mathrm{~m} / \mathrm{s}$. The overall velocity streamline of the internal flow field is shown in Fig. 10. According to the velocity distribution on the streamline, the velocity of the 
haemolymph notably increases when the fluid begins to collect, and the local flow area suddenly decreases. Additionally, the velocity is close to zero at the end of the metatarsus segment. Moreover, there are three inlets in this segment that eventually pool at the closed end. In addition, multiple occurrences of separation and mixing were observed in the process of haemolymph flow through the channels.

Based on the flow field characteristics of the spider leg, the hydraulic driving mechanism can be described as follows. The flow field nephogram which clearly shows the distribution of velocity and pressure shows that the fluid velocity at the end of the metatarsus segment is close to zero and that the pressure is negative pressure. The pressure difference between the end of the metatarsus and the inlet makes the fluid smoothly flow through the joint. However, because the end is closed, the increase in the fluid volume causes expansion, and the expansion continues to increase, triggering the rotation of the joint and the movement of the leg.

\section{Bionic hydraulic system and comparisons with other systems}

Blickhan and Barth (1985) noted the existence of lacunae (Fig. 11a) in the tibia of spiders, which provide rapid haemolymph transport during active and passive joint movement. Additionally, they simplified the channels and drew the circuit (Fig. 11b) to explain the fluid mechanics of the tibia. A simple hydraulic system based on our present work and on the flow path of the haemolymph in the channel is shown in Fig. 12. The hydraulic system is mainly composed of a constant-power variable piston pump, a multistage pressure-regulating circuit, a liquid resistance-regulating circuit and an actuating element. The constant power variable piston pump is used to ensure constant power, i.e. the product of pressure and flow is constant. When the load increases, more pressure is needed, and the flow rate decreases, and vice versa. Therefore, the constant-power variable piston pump can perform step-less voltage regulation to increase or decrease the pressure of the hydraulic system as the load changes. The multi-stage pressure regulation loop is in fact a three-stage pressure-regulating loop and is designed to satisfy the pressure of spiders in static condition, continuous and sudden motions. The system pressure is controlled by the main overflow valve, and the three-position four-way reverse valve is used to separately control the remote pressure-regulating valve. Therefore, the system has three types of pressure controls that represent the spider at rest, continuous movement and sudden movement.

There are mainly three types of liquid resistance: thin blade, slender pass and mixed-type resistance. 
The pressure loss due to slender pass liquid resistance is mainly caused by the decrease in pressure along the flow path. The loss of haemolymph flow in spiders mainly results from one-way resistance. In addition, the flow resistance can change because the outer edge of the flow channel is elastic. Therefore, adjustable slender pass liquid resistance is chosen to simulate the flow loss involved in hydraulic transmission. The basic bridge subnetworks in a liquid resistance network mainly include the full bridge liquid resistance subnetwork, half bridge liquid resistance subnetwork and $\pi$ bridge liquid resistance subnetwork. Each type of liquid resistance subnetwork has a variety of structural forms. The $\pi$ bridge liquid resistance network has one input control port and two output control ports. When the input parameters are invariant, two output parameters are adjusted by adjusting the variable liquid resistance. The A-type half bridge has only one input control port and one output control port. The electromagnetic reversing valve uses the suction force of the electromagnet to push the spool to change the working position of the valve. The electromagnetic reversing valve can be controlled by means of a button switch, a travel switch, a limit switch, etc. Electromagnetic reversing valves are generally used in applications where the pressure is not high and the flow rate is not large. It is necessary to use an electromagnetic reversing valve to achieve the function, which makes it easy to switch the pressure. If there is no electromagnetic reversing valve, it is impossible to change the pressure quickly. In Fig. 12, when the electromagnetic reversing valve on the left side is in the left position, the hydraulic cylinder is supplied with oil forward to cause the rod to extend. This action is equivalent to the spider's leg extension, and the spring force similar to the flexor pressure is used as the load. When the electromagnetic reversing valve is in the right position, the hydraulic cylinder is unloaded. This is equivalent to not supplying pressure to the spider legs. The spring force, that is, the flexor pulling force, pushes the hydraulic oil back to the fuel tank. This operation corresponds to flexing spider legs.

The circuit proposed by Blickhan and Barth (1985) is also drawn according to the flow channel in the tibia, and the flow in the proximal leg segments is approximated by a fluid resistance $R B$. Based on the circuit design, the haemolymph pressure, which is the only antagonizing agent that resists muscle forces, is produced in the arteries, muscular capillaries, and dorsal and dorsoventral channels of the lacunae. Moreover, as shown in Fig. 11, the arrows of the loop starting from the heart show that there are five routes in this circuit, which is in accordance with the system loop in our study. 


\section{Discussion}

The tibia-metatarsus joint containing the distal hydraulic joint was studied rather than the entire leg. An entire internal channel model of the leg should be established and investigated to understand the mechanisms underlying the efficient hydraulic transmission in spiders in the future. There is some draw back consisting of artefacts generated by the fixation process. The comparison of several spider samples will be given in the future study. In addition, the reasons for negative pressure may not be only the pseudovalues produced by CFD software, but also the cell deformation, muscle contraction during joint extension and so on. Furthermore, we will continue to explore the response of sudden changes in pressure to the flow and pressure distributions calculated by formulas, CFD simulations and bionic models. The haemolymph flow within other legs should also be studied and used for comparison to achieve a more comprehensive and systematic understanding of the associated mechanism. Only the principal concept of a hydraulic system based on the simulation results is presented without further details regarding how to develop such a system. The limitation of this hydraulic system is that there is no corresponding resistance value for each hydraulic resistance. After determining the size and relationship of the parameters of the hydraulic system, we will test the system. This may be the subjects of a forthcoming paper.

\section{Conclusion}

In this paper, various methods, including SEM and Micro-CT, were employed to investigate a spider leg, and a brief introduction to the methods used was provided. A novel approach to creating an accurate 3D model of the internal channel of a spider leg joint using UG combined with Micro-CT images was proposed. Two types of boundary conditions were used in the CFD simulation: pressure inlet and velocity inlet conditions. Mass flow rates using the two boundary conditions were compared with the theoretical values, and satisfactory agreement was observed from the velocity inlet boundary condition. Although the current calculation has many simplifications, the flow field analysis results obtained by this CFD method are in agreement with the theoretical values, so this CFD method is an effective and feasible analysis method. The high pressure areas (inlet, joint, closed leg end) and low pressures in between are also identified. Within cross-sections pressure varies strongly. The dorsal channel seems to be a low pressure area as it supplies the following leg joint. The different functions of the channels is substantiated by the velocity profiles. Such a relationship is also identified for the femur-patella joint. The mechanism 
of the flow inside the leg was analysed and a hydraulic system was designed based on the flow path of the haemolymph in the channel obtained through the simulation. The resulting system was not only consistent with the existing literature but also more developed than traditional systems and closer to actual hydraulic systems in the context of engineering. Thus, this approach provides a new method of designing and improving the performance of hydraulic systems. This hydraulic system is mainly to simulate the actions of spider legs, which is a preliminary analysis of the complex hydraulic system inside spider legs laying a groundwork for further research. In this study, we used the general terms in hydraulics to explain the working principle underlying spider legs for general readers. Meanwhile, we also used dedicated CFD modelling to reveal the hydraulic mechanism in detail.

\section{Acknowledgement}

This work was partly supported by the National Natural Science Foundation of China [grant number 51675219], the China Postdoctoral Science Foundation [grant number 2016M590261] and the Key Scientific and Technological Project of Jilin Province [grant number 20170204066GX]. All procedures performed in studies involving animal care and collection were in accordance with laws, ordinances, and the ethical standards of our institution and government.

\section{References}

Alexander A (1967) Problems of limb extension in the scorpion, Opisthophthalmus latimanus Koch. Trans R Soc S Afr 37(3):165-181. https://doi.org/10.1080/00359196709519065

Anderson JF, Prestwich KN (1975) The fluid pressure pumps of spiders (Chelicerata, Araneae). Z Morph Tiere 81(4):257-277. https://sci-hub.tw/10.1007/bf00298488

Biasetti J, Hussain F, Gasser TC (2011) Blood flow and coherent vortices in the normal and aneurysmatic aortas: a fluid dynamical approach to intra-luminal thrombus formation. J R Soc Interface 8(63):1449-1461. https://doi.org/10.1098/rsif.2011.0041

Blickhan R, Barth FG (1985) Strains in the exoskeleton of spiders. J Comp Physiol A 157(1):115-147. https://ink.springer.com/article/10.1007/BF00611101

Christians W, Stefan R (2010) Evolutionary morphology of the circulatory system in Peracarida (Malacostraca; Crustacea). Cladistics 26(2):143-167. https://sci-hub.tw/10.1111/j.10960031.2009.00278.x

Chu CX, Ma WX (2015) Engineering machinery hydraulic and hydraulic transmission: hydraulic volume. Chemical Industry Press, China

Clarke J (1986) The comparative functional morphology of the leg joints and muscles of five spiders. Bull Br Arachnol Soc 7(2):37-47. http://europepmc.org/abstract/AGR/IND86060130 
Ho ST, Hutmacher DW (2006) A comparison of micro CT with other techniques used in the characterization of scaffolds. Biomaterials 27(8):1362-1376. https://sci-hub.tw/10.1016/j.biomaterials.2005.08.035

Huckstorf K, Kosok G, Seyfarth E-A, Wirkner CS (2013) The hemolymph vascular system in Cupiennius salei (Araneae: Ctenidae). Zool Anz 252(1):76-87. https://www.sciencedirect.com/science/article/pii/S0044523112000174

Karakurt T, Durdu A, Yilmaz N (2015) Design of six legged spider robot and evolving walking algorithms. IJMLC 5(2):96-100. http://www.ijmlc.org/index.php?m=content\&c=index\&a $=$ show\&catid $=56 \&$ id $=552$

Kropf C (2013) Hydraulic System of Locomotion. In: Nentwig W (eds) Spider Ecophysiology. Springer, Berlin, Heidelberg, pp 43-56. https://doi.org/10.1007/978-3-642-33989-9_4

Li YS, Ausama A, Dan S, Carlo M (2012) Abigaille II: Toward the development of a spider-inspire climbing robot. Robotica 30(1):79-89. https://www.researchgate.net/publication/259417011_Abigaille_II_Toward_the_development_of_a_spider-inspired_climbing_robot

Lira C, Menon C, Kianfar K, Scarpa F, Mani M (2008) Mining smartness from the hydraulic system of spiders: a bioinspired actuator for advanced applications. Adv Sci Technol 58:114-119. https://doi.org/10.4028/www.scientific.net/AST.58.114

Liu CB, Liu CS, Ma WX (2015) Rans, detached eddy simulation and large eddy simulation of internal Torque converters flows: A comparative study. Eng Appl Comp Fluid 9:114-125. http://doi.org/10.1080/19942060.2015.1004814

S MMFRS, Harding MJP (2009) Hydrostatic pressure and leg extension in arthropods, with special reference to arachnids. J Nat Hist 1(3):161-182. https://doi.org/10.1080/00222935808650934

Menon C, Lira C (2006) Active articulation for future space applications inspired by the hydraulic system of spiders. Bioinsp Biomim 1(2):52-61. https://iopscience.iop.org/article/10.1088/17483182/1/2/003/meta

Parry DA, Brown RHJ (1959b) The jumping mechanism of salticid spiders. J Exp Biol 36:654-664

Paul R, Tiling K, Focke P, Linzen, B (1989) Heart and circulatory functions in a spider (Eurypelma californicum): the effects of hydraulic force generation. J Comp Physiol B 158(6):673-687. https://ink.springer.com/article/10.1007/BF00693005

Reußenzehn S (2010) Mechanical design of the legs of Dolomedes aquaticus - Novel approaches to quantify the hydraulic contribution to joint movement and to create a segmented 3D spider model. University of Otago, Otago. http://hdl.handle.net/10523/404

Sensenig AT (2003) Mechanics of cuticular elastic energy storage in leg joints lacking extensor muscles in arachnids. J Exp Biol 206(4):771-784. https://doi.org/10.1242/jeb.00182

Shultz JW (1991) Evolution of locomotion in arachnida the hydraulic pressure pump of the giant whipscorpion, Mastigoproctus giganteus (Uropygi). J Morphol 210(1):13-31. https://doi.org/10.1002/jmor.1052100103

Shultz WS (2010) Muscular anatomy of the giant whipscorpion Mastigoproctus giganteus (Lucas) (arachnida: uropygi) and its evolutionary significance. J Linn Soc London, Zool 108(4):335-365. https://doi.org/10.1006/zjls.1993.1029

Siebert T, Weihmann T, Rode C, Blickhan R (2010) Cupiennius salei: biomechanical properties of the tibia-metatarsus joint and its flexing muscles. J Comp Physiol B 180(2):199-209. https://link.springer.com/article/10.1007/s00360-009-0401-1

Spröwitz A, Göttler C, Sinha A, Caer C, Öoztekin M Petersen K, Sitt M (2017) Scalable pneumatic and 
tendon driven robotic joint inspired by jumping spiders. IEEE International Conference on Robotics and Automation (ICRA):64-70. http://dx.doi.org/10.1109/ICRA.2017.7988692

Stegen E, Grieshaber MK (2001) Adenosine increases ventilation rate, cardiac performance and haemolymph velocity in the American lobster Homarus americanus. J Exp Biol 204(Pt 5):947-957. http://jeb.biologists.org/content/204/5/947.short

Stewart DM, Martin AW (1974) Blood pressure in the tarantula, Dugesiella hentzi. J Comp Physiol A 88(2):141-172. https://link.springer.com/article/10.1007/BF00695405

Wang F (2004) Computational fluid dynamics analysis: Principles and applications of CFD software. Tsinghua University press, China

Palmgren P (1981) The mechanism of the extrinsic coxal muscles of spiders. Ann Zool Fenn 18(4):203207. https://www.jstor.org/stable/23734536

Whitehead WF, Rempel JG (1959) A study of the musculature of the black widow spider, Latrodectus mactans (FABR.) Can J Zool 37(6):831-870. https://doi.org/10.1139/z59-084

Wirkner CS, Huckstorf K (2013) The circulatory system of spiders. In: Nentwig W (eds) Spider Ecophysiology. Springer, Berlin, Heidelberg, pp 15-27. https://doi.org/10.1007/978-3-642-33989-9_2

$\mathrm{Xu}$ YZ (2013) Interpretation and reflection on the development roadmap of hydraulic technology in

China. Fluid Power Transmission and Control 1:1-6. http://www.cqvip.com/QK/87252X/201301/1002813394.html

Yang HY, Zhou H (2013) New achievements in water hydraulics. Chinese Hydraulic and pneumatic 2:16

Yu YJ, Wang Y, Xu SL (2015) CFD simulation of the two-phase flow of blood and thrombus flow in blood vessels. J. Chem. Eng. Chin. Univ. 4:992-996. https://doi.org/10.3969/j.issn.10039015.2015.04.030

Zentner L (2013) Modelling and application of the hydraulic spider leg mechanism. In: Nentwig W (eds) Spider ecophysiology. Springer, Berlin, Heidelberg, pp 451-462. https://doi.org/10.1007/978-3-64233989-9_34

Zhang Y (1999) Second edition of fluid mechanics. HEP, China

\section{Tables:}

Table 1 the inlet pressure values

\begin{tabular}{lccc}
\hline Velocity $(\mathrm{m} / \mathrm{s})$ & 0.2 & 0.3 & 0.4 \\
\hline $\mathrm{P}_{1}\left(\mathrm{P}_{2}=2500 \mathrm{~Pa}\right)$ & 2506 & 2508 & 2511 \\
$\mathrm{P}_{1}\left(\mathrm{P}_{2}=5300 \mathrm{~Pa}\right)$ & 5306 & 5308 & 5311 \\
$\mathrm{P}_{1}\left(\mathrm{P}_{2}=9800 \mathrm{~Pa}\right)$ & 9806 & 9808 & 9811 \\
\hline
\end{tabular}

Table 2 Comparison of mass flow rates between the simulation with two boundary conditions and the theoretical values 


\begin{tabular}{cccc}
\hline Velocity $(\mathrm{m} / \mathrm{s})$ & 0.2 & 0.3 & 0.4 \\
\hline $\begin{array}{c}Q_{\mathrm{m}} \text { of Theoretical calculation }(\mathrm{kg} / \mathrm{s}) \\
Q_{\mathrm{m}} \text { of Simulation with pressure inlet condition } \\
(\mathrm{kg} / \mathrm{s})\end{array}$ & $2.8 * \mathrm{E}-3$ & $4.2 * \mathrm{E}-3$ & $5.6 * \mathrm{E}-3$ \\
$\begin{array}{c}2.36 * \mathrm{E}-9 \\
Q_{\mathrm{m}} \text { of simulation with velocity inlet condition } \\
(\mathrm{kg} / \mathrm{s})\end{array}$ & $4.03 * \mathrm{E}-9$ & $4.48 * \mathrm{E}-9$ \\
\hline
\end{tabular}

Figures:
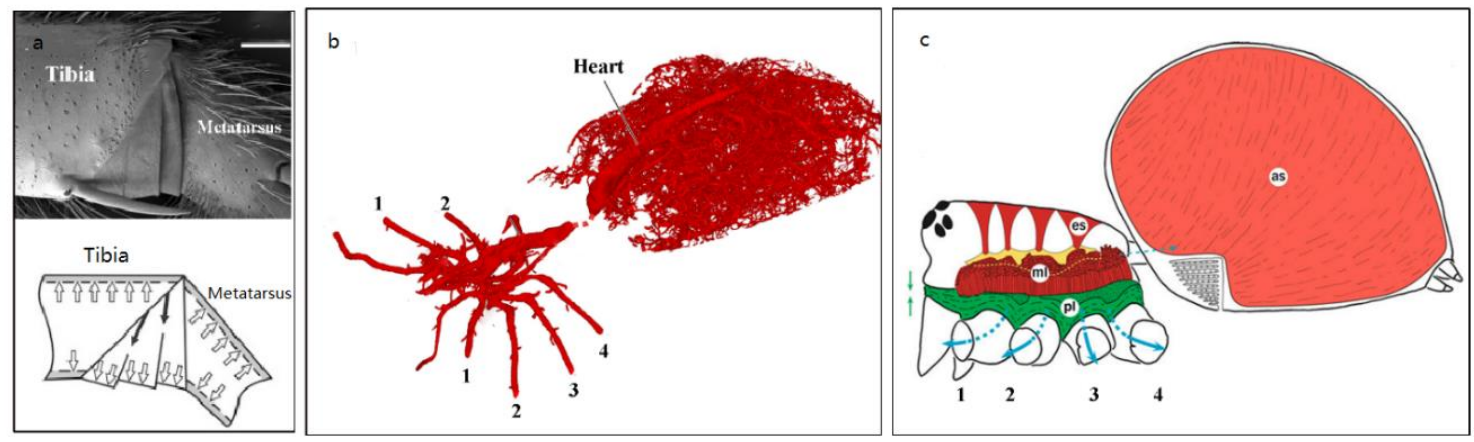

Fig. 1 Illustration of the hydraulic drive system of the spider. (a) Mechanical design of the articular membrane in the tibia-metatarsus joint (Blickhan and Barth 1985). (b) The haemolymph vascular system (Huckstorf et al. 2013). (c) Simplified schematic illustration of the putative main elements of the haemolymph pressure producing system in a spider leg (musculi laterales $(\mathrm{ml})$ or endosternal suspensor (es), pleura (pl), and abdominal sac (as)) (Whitehead and Rempel 1959; Anderson and Prestwich 1975; Whitehead and Rempel 1981). 


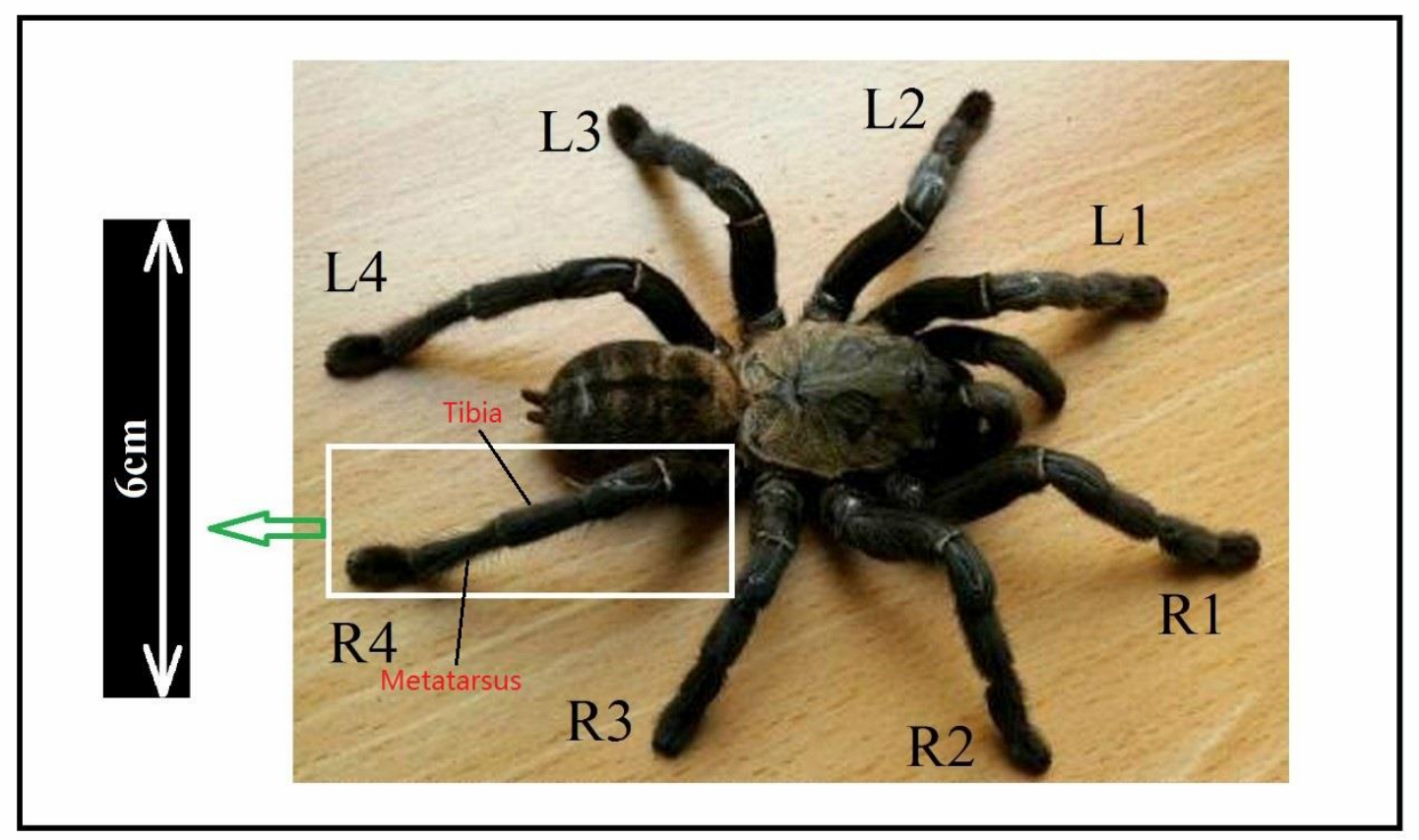

Fig. 2 Bird-catching spider from Vietnam used for experiments (the length of the fourth leg on the right is $6 \mathrm{~cm})$.

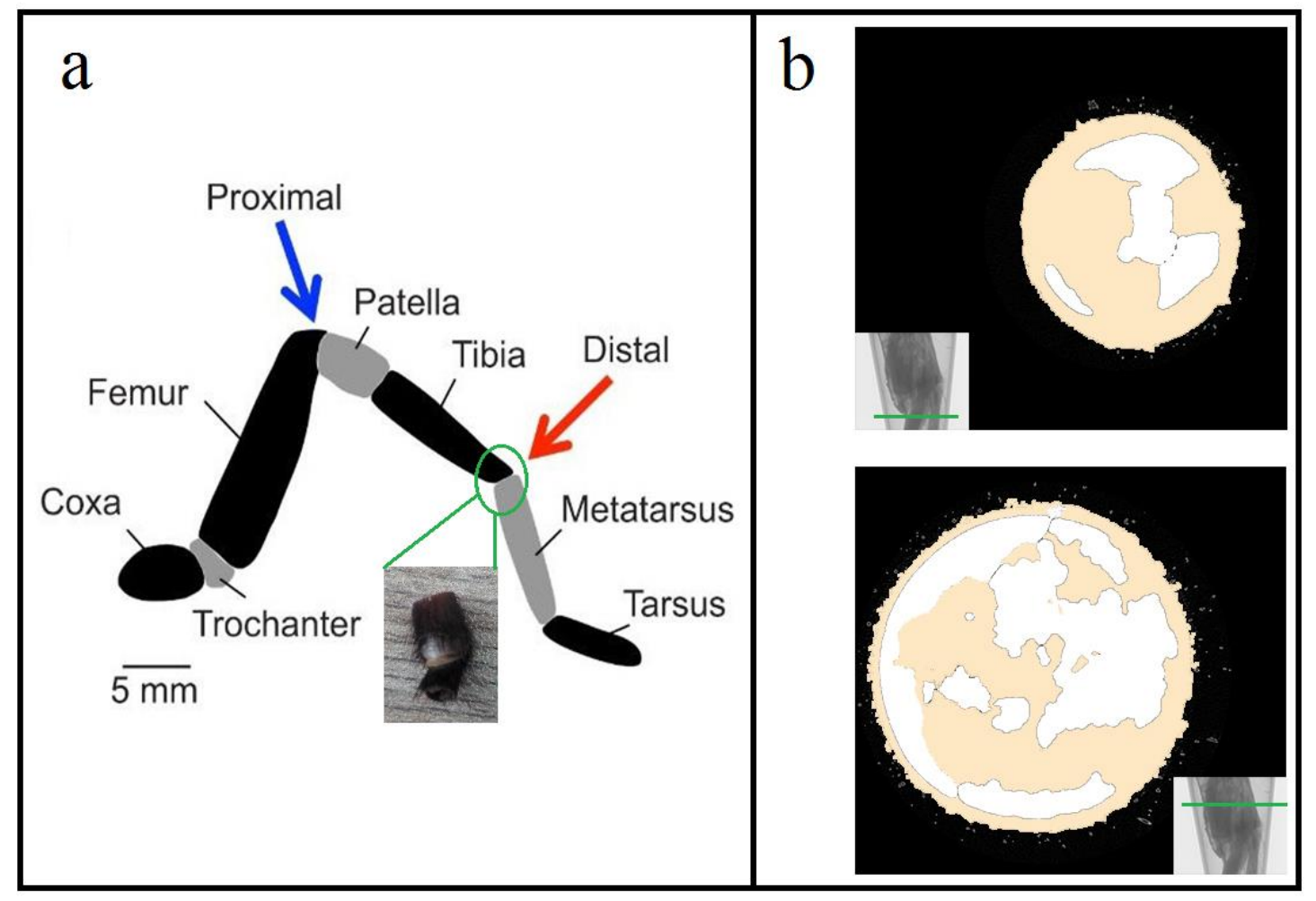

Fig. 3 Micro-CT images at different positions of the tibia-metatarsus joint. (a) The tibia-metatarsus joint selected in the experiment (b) Micro-CT images (The entities shown in the picture actually contain shells and muscles. Irregular holes are clearly visible in each cross section and constitute the channels for fluid 
transport; the green lines represent the scanning positions).

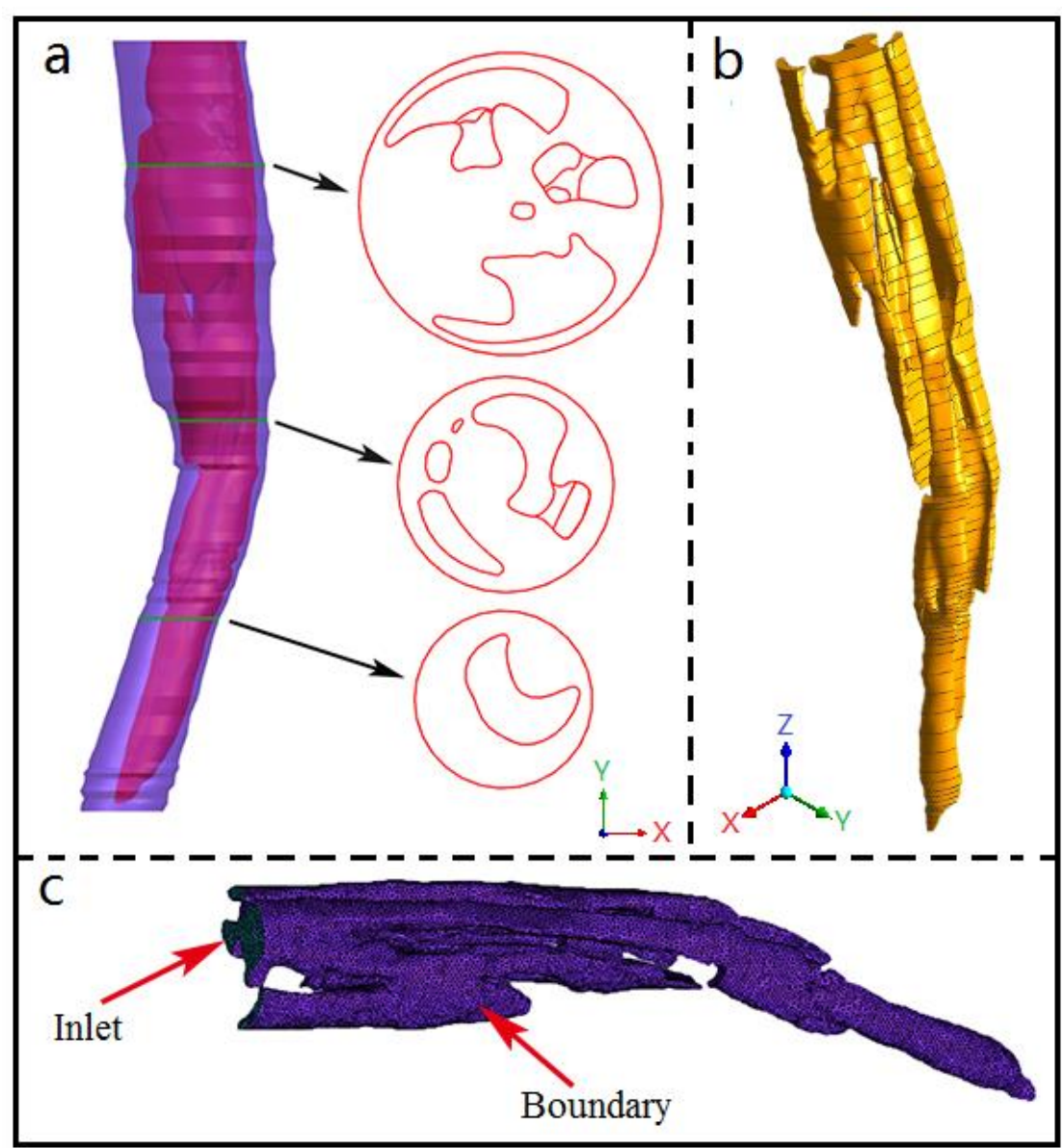

Fig. 4 The reconstructed model of the tibia-metatarsus joint. (a) Channel distribution on three cross sections of tibia-metatarsus joint (purple marks the exoskeleton, green marks section position, the figures to which the arrow points represent the shape of the section). (b) The internal flow channel model. (c) Setting of boundary conditions.

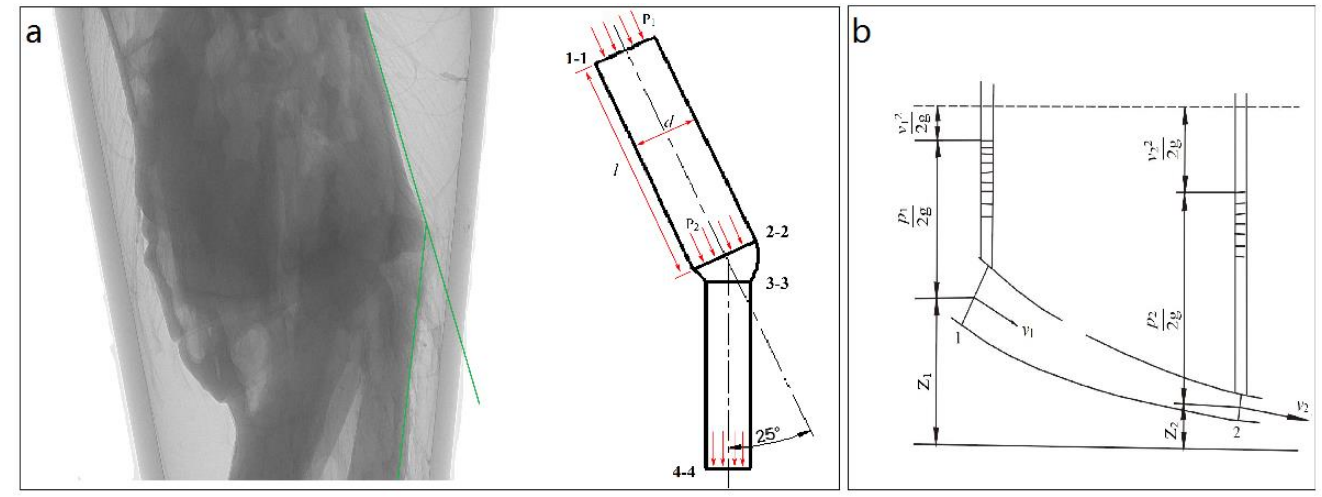

Fig. 5 Simplification of the joint. (a) The tibia-metatarsus joint with the simplified model (1-1marks 
inlet, 2-2 marks the distal end of the tibia segment, 3-3 marks the proximal initial position of the metatarsus segment, 4-4 marks closed ends, $25^{\circ}$ is the bending angle of the joint). (b) The flow of fluid in a pipe (the relationship between the expressions is shown in Equation (4)).
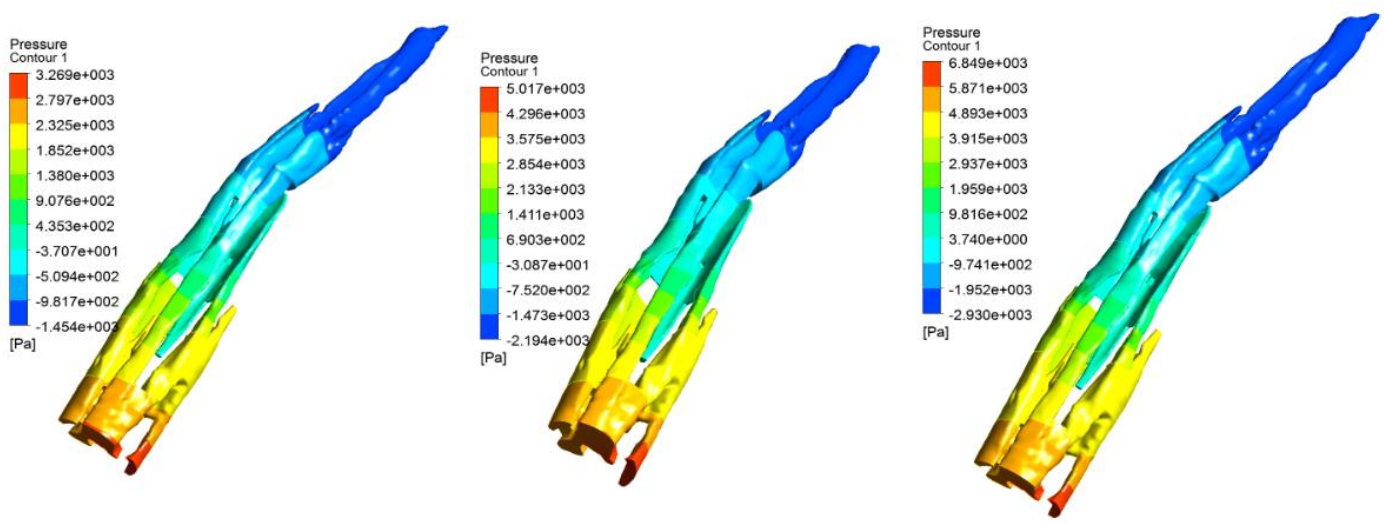

Fig. 6 The overall pressure distribution of the flow field based on the previous pressure boundary conditions (i.e., pressures of $2500 \mathrm{~Pa}, 5300 \mathrm{~Pa}$, and $9800 \mathrm{~Pa}$ ) in the tibia-metatarsus joint

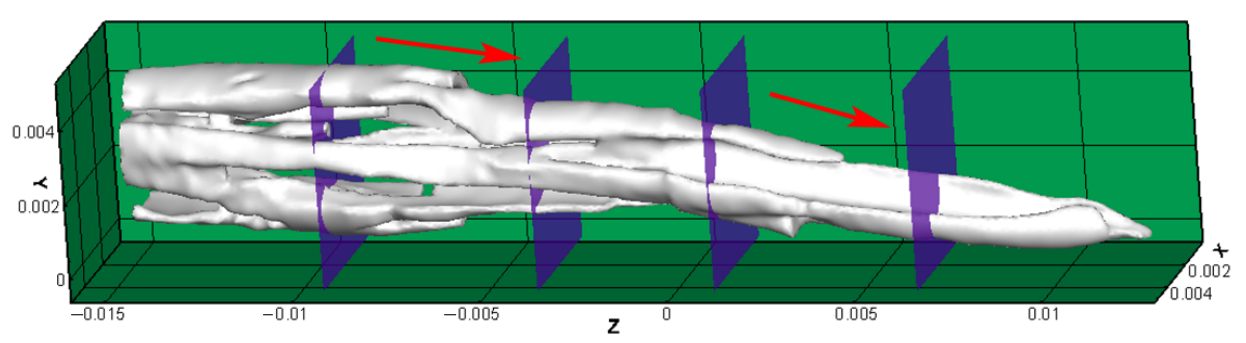

a
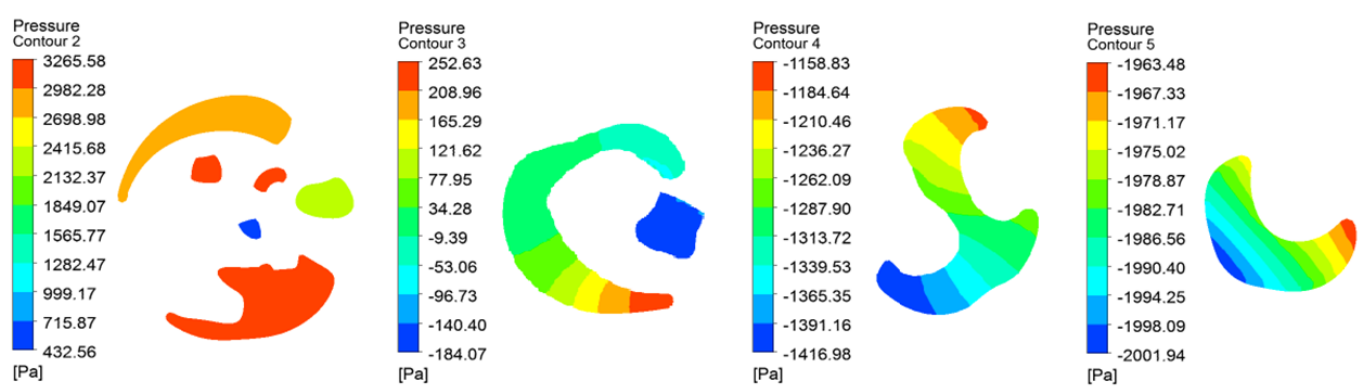

b
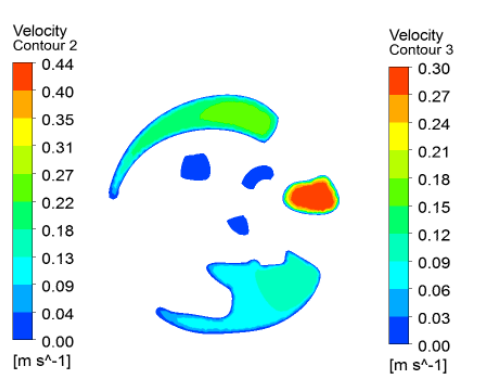

$$
Z=-0.0092 m
$$
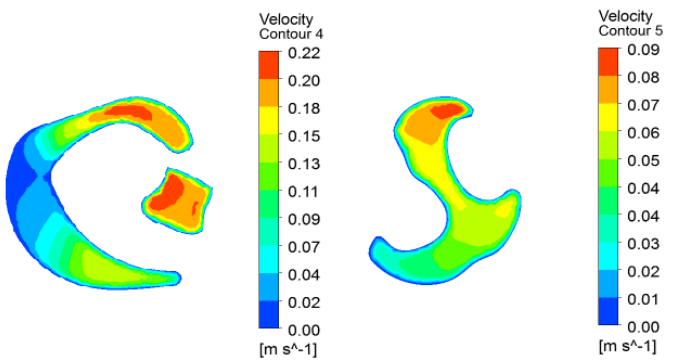

$Z=0.0012 m$

$\mathrm{Z}=0.0066 \mathrm{~m}$

Fig. 7 Flow field distribution at four cross sections of the tibia-metatarsus joint. (a) The local pressure distribution. (b) The local velocity distribution. 


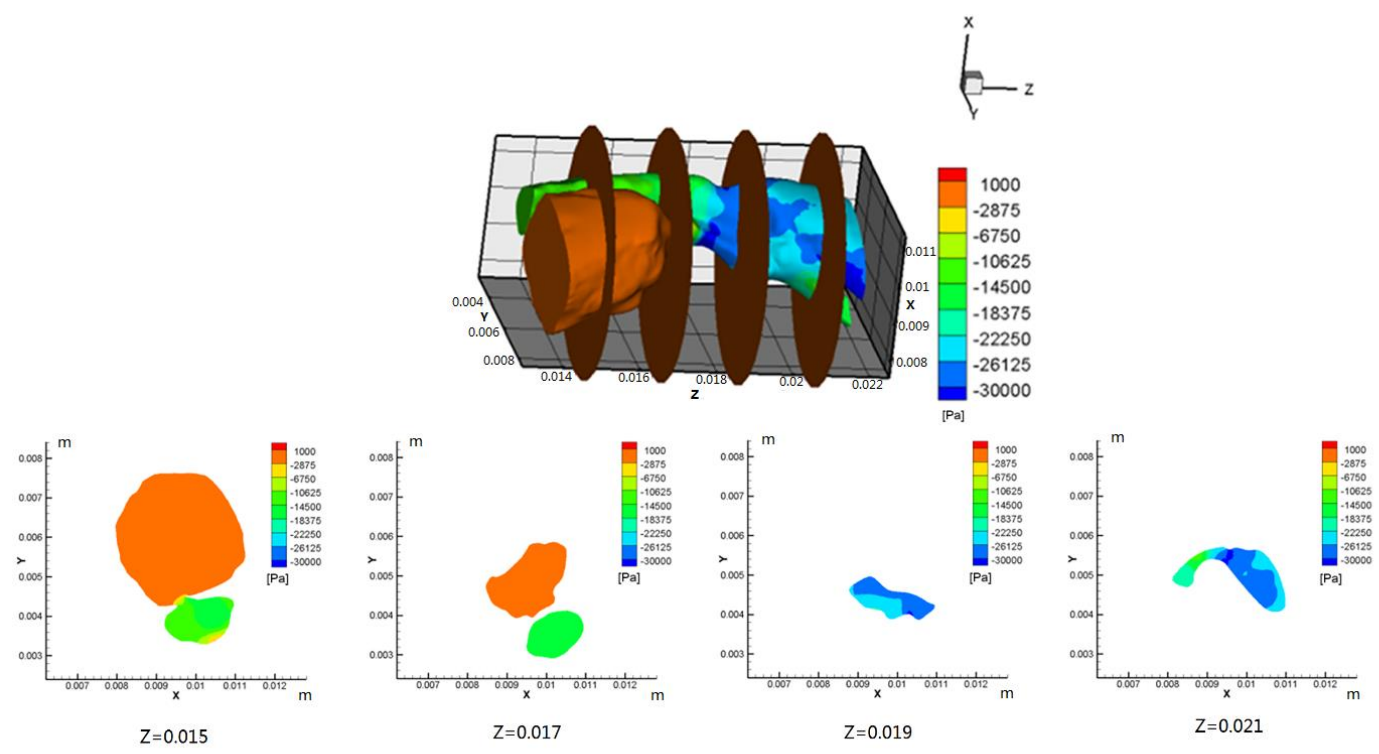

Fig. 8 Pressure distribution at four cross sections of the femur-patella joint.

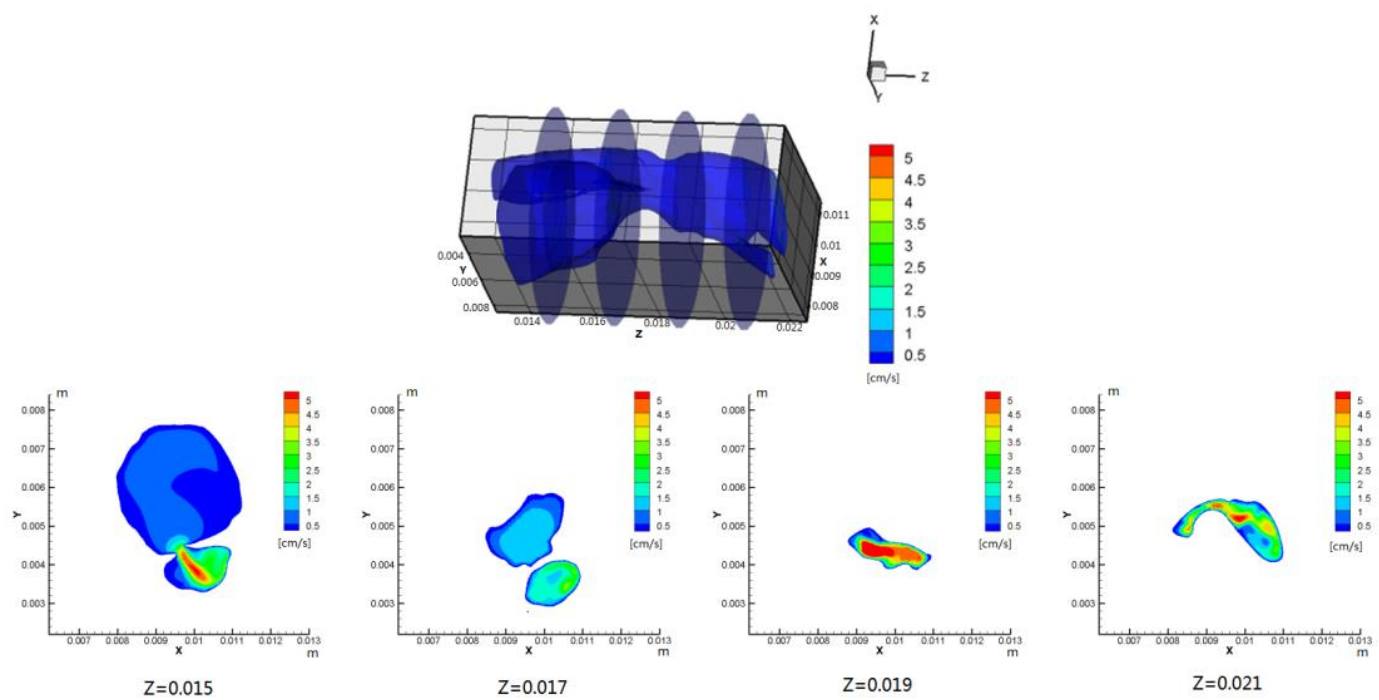

Fig. 9 Velocity distribution at four cross sections of the femur-patella joint. 

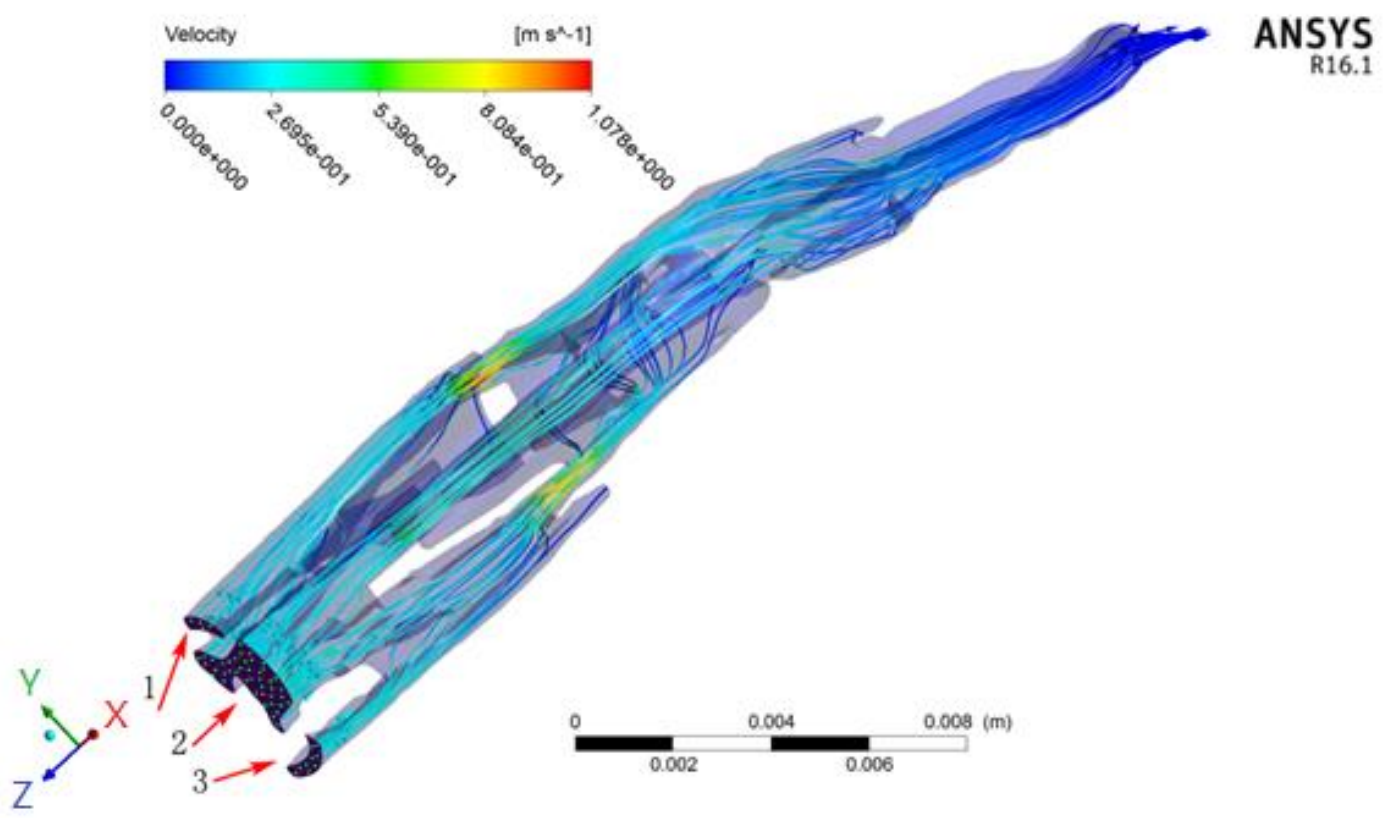

Fig. 10 The velocity streamline of the tibia-metatarsus joint ( 1 to 3 represent three imports; the two branches of inlet 2 near the initial end converge with inlet 1 and inlet 3 , respectively; the velocity of flow in the position with relatively small cross section area is obviously accelerated).
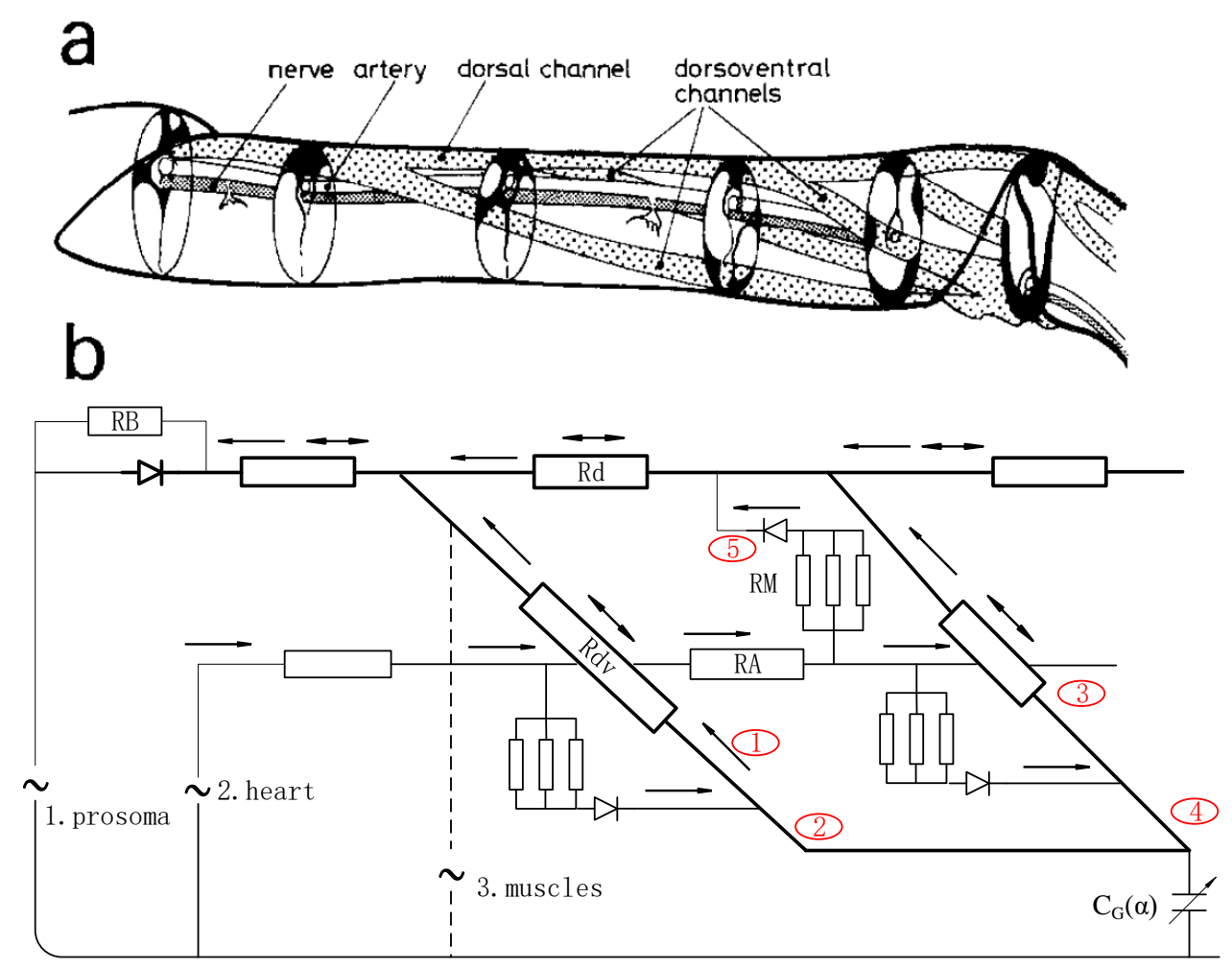
Fig. 11 The circuit proposed by Blickhan and Barth (1985). (a) Lacunae in the tibia of spiders. (b) the circuit explaining fluid mechanics in the tibia (RA is fluid resistance of the arteries; RB is resistance of the channels in the proximal leg segments; $\mathrm{RD}$ is fluid resistance of the dorsal; $\mathrm{RD}_{\mathrm{v}}$ is resistance of dorsoventral hemolymph channels; $\mathrm{RM}$ is fluid resistance of the muscular capillaries; $\mathrm{C}_{\mathrm{G}(\alpha)}$ is volume displacement of the articular membrane; 1 to 3 are three sources of pressure; (1) to (5) are the five circuits in the loop).

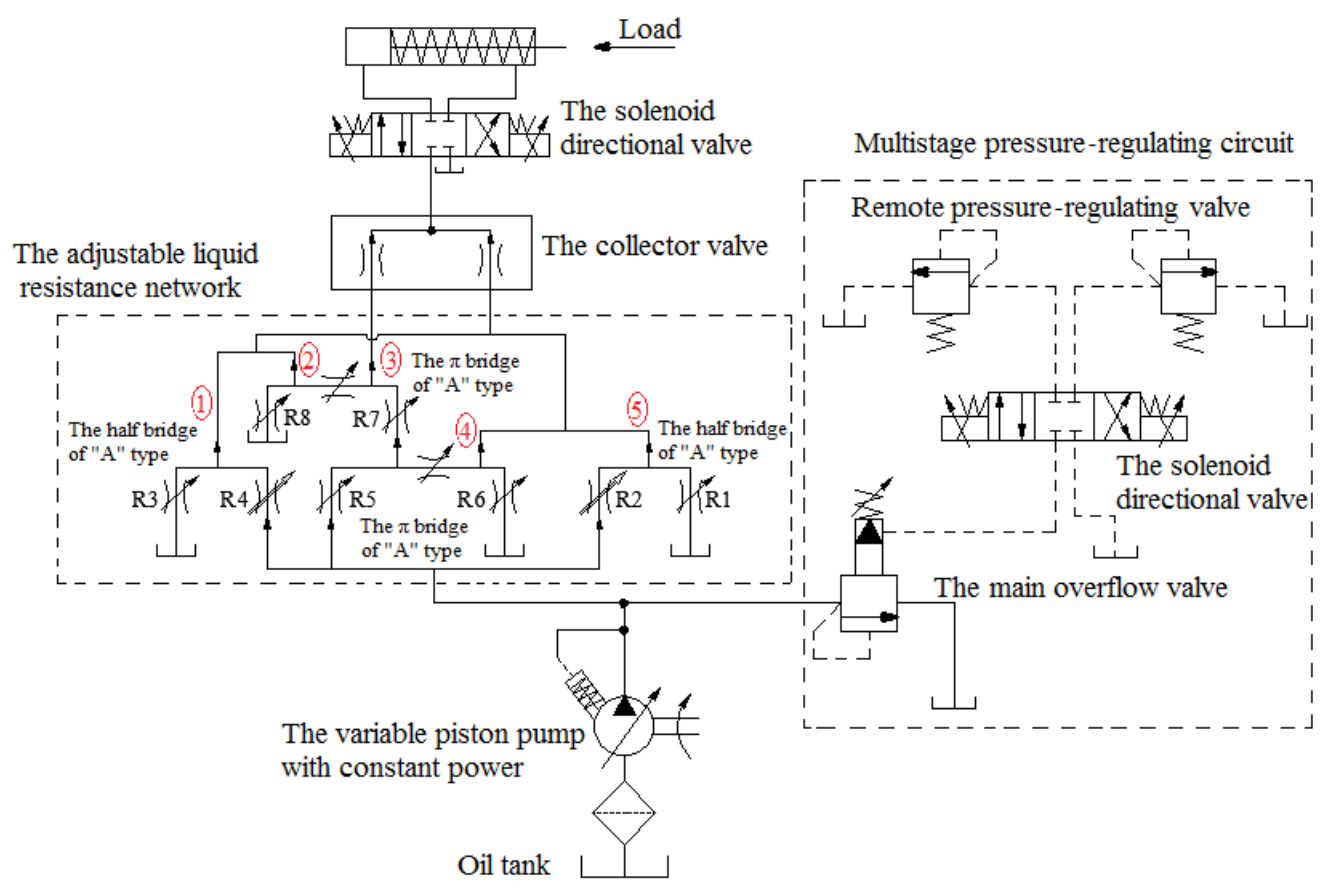

Fig. 12 The bio-inspired hydraulic system (R1 to R7 represent 7 kinds of liquid resistance; (1) to (5) are the five circuits in the loop). 